\title{
Alain Lescart, Splendeurs et misères de la grisette. Évolution d'une figure emblématique
}

\section{Philippe Andrès}

\section{(2) OpenEdition}

1 Journals

\section{Édition électronique}

URL : http://journals.openedition.org/studifrancesi/7600

DOI : 10.4000/studifrancesi.7600

ISSN : 2421-5856

Éditeur

Rosenberg \& Sellier

\section{Édition imprimée}

Date de publication : 1 décembre 2009

Pagination : 639-640

ISSN : 0039-2944

\section{Référence électronique}

Philippe Andrès, "Alain Lescart, Splendeurs et misères de la grisette. Évolution d'une figure

emblématique », Studi Francesi [En ligne], 159 (LIII | III) | 2009, mis en ligne le 30 novembre 2015, consulté le 09 janvier 2021. URL : http://journals.openedition.org/studifrancesi/7600 ; DOI : https:// doi.org/10.4000/studifrancesi. 7600

Ce document a été généré automatiquement le 9 janvier 2021.

\section{(c)}

Studi Francesi è distribuita con Licenza Creative Commons Attribuzione - Non commerciale - Non opere derivate 4.0 Internazionale. 


\title{
Alain Lescart, Splendeurs et misères de la grisette. Évolution d'une figure emblématique
}

\author{
Philippe Andrès
}

\section{RÉFÉRENCE}

ALAIN LESCART, Splendeurs et misères de la grisette. Évolution d'une figure emblématique, Paris, Honoré Champion, 2008, pp. 333.

1 Ce volume, qui témoigne à la fois d'une recherche fouillée et d'un esprit de synthèse, dresse le portrait de la grisette qui «emblématise les luttes de la classe populaire en vue de l'acquisition d'une plus grande indépendance sociale et économique» (p.7). Dans une première partie, «Étude du modèle français» (pp. 9-245), Alain Lescart montre la genèse de l'«élaboration d'une figure du $\mathrm{XVII}^{\mathrm{e}}$ au $\mathrm{XVIII}^{\mathrm{e}}$ siècle» (pp 11-38). En effet le terme de "grisette» apparaît dans le dictionnaire de Furetière et se retrouve chez La Fontaine. Mais c'est au siècle des Lumières que la grisette se trouve «associée au monde des marchandes de mode» et peu à peu un "glissement progressif» (p. 30) s'opère vers «la femme entretenue». Le chapitre 2, «La grisette au dix-neuvième siècle» (pp. 39-96), développe une analyse du personnage féminin avec ses différents avatars comme la lorette, «un alter ego plus antipathique» (p. 43). Le terme lui-même recouvre une réalité sociologique plus étendue qu'auparavant: chez Mercier, il s'agit d'une jeune fille pauvre et couturière, libre de moeurs. La grisette, ayant bénéficié de la loi Guizot, va s'enrichir des lumières de l'instruction au cours des années 1840. Sociologiquement elle appartient à la classe ouvrière, et non pas au prolétariat des usines textiles. Au chapitre 3, «La grisette dans les arts populaires» (pp.97-150), c'est le rôle de la chanson qui est mis en exergue par A. Lescart. Il étudie avec minutie la Société du Caveau moderne, relancée en 1805 où triomphe la chanson épicurienne. Béranger n'est «ni le seul, ni le premier à s'intéresser à la grisette» (p. 103), mais c'est lui qui incarne le mieux l'esprit de la Révolution française. La lisette, quant à elle, se retrouve dans les 
chansons bacchiques, puis devient un personnage plus politique, voire nationaliste. Elle incarne un modèle désormais traditionnel dans les lithographies, notamment celles d'Henry Monnier, sans oublier la série «Grisettiana» publiée en mai 1829. Mais la grisette se transforme en un personnage tragique pendant la Monarchie de Juillet, comme le montre le chapitre 4 «Grisette, danse et romantisme» (pp.151-211). Grâce aux bals populaires, elle devient un type de femme choyé par les romans populaires comme ceux de Paul de Kock. C'est le règne du chahut et du cancan. La lorette, pour sa part, incarne désormais une nouvelle métamorphose féminine. Pour synthétiser tout cela, un schéma narratif développe le prototype d'une «autopsie d'une grisette» (p.166). La mélancolie et la tuberculose seront les deux maladies symboliques inhérentes au personnage allant jusqu'au sacrifice suprême. A. Lescart analyse finement le cas de Mimi Pinson, mais s'intéresse également aux Mystères de Paris et à $L a$ Vie de Bohème. Le chapitre 5, "Grisettes et réalisme» (pp. 213-247) souligne le lien entre la grisette et le monde de la prostitution. Le corps symbolique de la grisette s'érotise, dans les chansons populaires, en «femme-chiffon» (p. 225). Un autre schéma, également intéressant, dresse l'architecture de La Dame aux camélias et met à nu «la morphologie de la courtisane amoureuse» (p. 240). Dans la seconde moitié du xix ${ }^{e}$ siècle, la grisette disparaît de la «tradition de la femme facile et amoureuse» (p. 246).

2 La deuxième partie de l'ouvrage, beaucoup plus courte, ouvre des perspectives sur «l'exportation du modèle grisette» (pp. 251-303), notamment en terre anglo-saxonne. L'on retrouve l'influence capitale de Sterne au xvIII ${ }^{\mathrm{e}}$ siècle et dans les journaux américains recensés par l'auteur se dessine «une nouvelle icône faisant de la parisienne un être romantique, passionné, tragique, aimant et désintéressé» (p. 259). Dans le domaine littéraire, il revient à Charlotte Brontë de faire vivre ce type de femme. Dans son roman Villette (1853), la grisette défie le monde d'une société masculine. Puis il est procédé à une rapide présentation de «la grisette tombée en camélia» en une lecture parallèle entre Sand, Dumas fils et Gaskell. La grisette a donc, outre Atlantique, exercé un pouvoir différent «sur les hommes et sur les femmes de langue anglaise» (p. 295). Dans sa conclusion générale (pp.297-303), A. Lescart souligne l'importance de la grisette dans les rapports sociaux. Le corps symbolique de la grisette se métamorphose depuis l'Ancien Régime (corps érotique pour l'aristocrate) et se transforme sous la Restauration en modèle moral. Puis sous la Monarchie de Juillet, la grisette devient un personnage romantique et le réalisme donne une version "catastrophiste» de la grisette (p. 300). A. Lescart l'affirme lui-même: «L'intérêt de cette étude réside dans les phénomènes culturels qui accompagnent la figure emblématique de la grisette et sa participation à la formation d'une identité nationale» (p. 302). Cette recherche, qui se situe au carrefour d'une approche thématique et sociologique, nous a semblé intéressante. Cependant, nous avons pu déplorer le manque de soin parfois dans la typographie (notes, américanismes dans la langue, accents oubliés et autres coquilles). La bibliographie est honnête. Nous pouvons recommander la lecture de cet ouvrage qui, sans être exhaustif (tel n'est pas son objectif), invite à la poursuite d'une analyse sociologique de la femme au XIX ${ }^{e}$ siècle. 